\title{
In-Situ Dynamic Characterization of Energy Storage and Conversion Systems
}

\author{
Ying Zhu, Wenhua H. Zhu and Bruce J. Tatarchuk
}

Additional information is available at the end of the chapter

http://dx.doi.org/10.5772/52415

\section{Introduction}

The combustion of fossil fuels predominates in the commercial implementation of energy conversion and power generation. However, it brings severe problems to the environment due to inevitably incomplete combustion. Meanwhile, the price of fossil fuels keeps increasing due to the depletion of natural resources. The growing concerns of global warming, as well as the reducing availability of fossil fuels, require replacements of gasoline and diesel fuels, such as Fischer-Tropsch synthetic fuels [1-3], biofuels [4, 5], and hydrogen fuel $[6,7]$. The thermal conversion efficiency of a traditional automobile engine is between $17 \%$ and $23 \%$ [8], limited by the intrinsic characteristics of Carnot cycle. Energy storage and conversion systems with low/zero emissions, high efficiency, and great durability are required by the development of sustainable energy and power economy.

The development of commercial applications of electrical vehicles (EVs) or hybrid electrical vehicles (HEVs) was propelled by increasing demands of an on-board rechargeable energy storage system. The advanced vehicle systems or processes with higher energy efficiency are preferred to use for saving fuels and improving the mileage of per unit fuel consumed. Hybrid power trains reduce undesirable emissions and also have their potential to improve fuel economy significantly. A highly efficient engine can charge the battery pack and propel the vehicle at the same time. The battery power assists the engine acceleration or propels the vehicle efficiently on its own at low speeds [9]. The battery pack is also returned with some energy from the electric motor, which is served as another generator in the regenerative braking or coasting mode. Therefore, the battery burst charge acceptance during frequent braking and power output capability during heavy acceleration are significantly important for the HEV fuel efficiency and engine emissions.

In addition to the on-board energy storage system, the development of energy conversion system explored another solution instead of combustion engines. A highly efficient 
approach of energy conversion enhances the application of hydrogen storage in many fields. Fuel cells can convert the energy stored in hydrogen to electricity without combustion at a higher level of energy efficiency. Furthermore, hydrogen fueled cells can produce electricity with almost zero emissions comparing to other energy conversion technologies. This is also beneficial to reduce the $\mathrm{CO}_{2}$ emissions.

It is significantly important to obtain deep understanding of energy storage and conversion systems to approach both technical and commercial breakthrough in sustainable energy development. The purpose of system characterization is to find out how and to what degree the properties, kinetics, and other effects of a system influence its performance. The understanding of system performance also provides basis for system diagnosis to distinguish good ones from degraded ones. For a rechargeable battery, main performance limiting factors include actual capacity, rate performance, state-of-charge (SoC) and state-ofhealth $(\mathrm{SoH})$. While for a fuel cell, attentions are mainly paid to electrode structures, electrolyte fabrications, conductivity mechanisms, reaction limitations, catalytic poisoning, and cell degradations.

Electrochemical Impedance Spectroscopy (EIS) is a sensitive, powerful, and non-destructive analytical technique capable of assessing the dynamic response of an electrochemical system. It is generally conducted by superimposing an $a c$ signal on the $d c$ output of the working system and measuring its resulting ac signal over a spectrum of frequencies. The obtained impedance is simulated by an equivalent circuit (EC) diagram, which produces a similar load response to the working system. Different types of circuit elements along with different values are able to simulate various processes occurring in the measuring system. A well validated EC diagram can be employed to mechanistically discriminate the kinetic and mass transfer processes that limit system outputs.

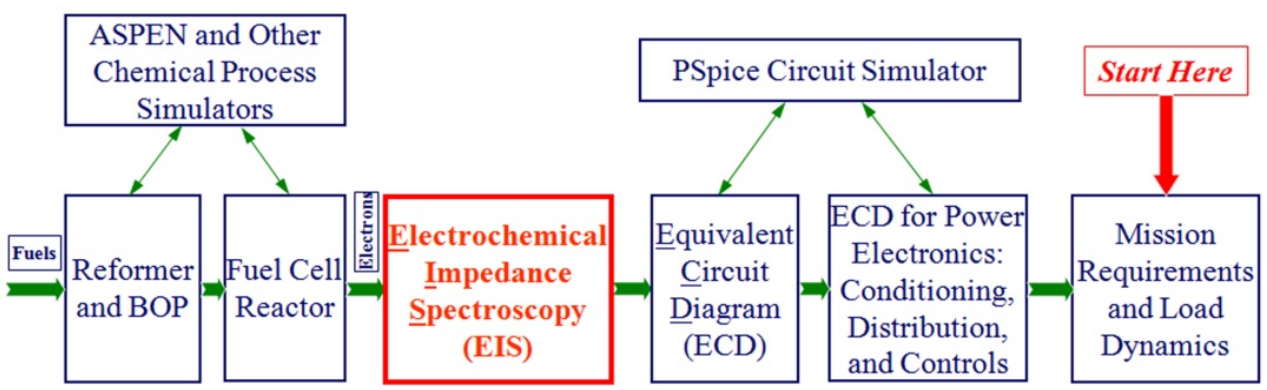

Figure 1. Methodology for integrated system design, operation, and control.

The great prospects of impedance analysis and EC simulation of energy storage and conversion systems lie in characterizing chemical reactors in terms of electronics. Chemical, electrochemical, and physical processes occurring in energy storage and conversion systems, such as batteries and fuel cells, are simulated in chemical process simulators (ASPEN for example), studying mass balance, thermodynamics, and kinetics of systems. Meanwhile, electrical circuits are simulated in analog circuit simulators (PSpice for example) to predict 
circuit behaviors and provide industrial standard solutions including the non-linear transient analysis for voltage and current versus time. It is EIS that establishes the connection between chemical processes (ASPEN) and power electronics (PSpice). The in-situ real-time measuring technique as well as EC simulation distinguishes the real processes occurring in batteries and fuel cells and interprets them into electronic circuit elements for system simulation. In this way, EIS systematically provides a competent methodology (Figure 1) for integrated system design, operation, and control.

This chapter highlights the competence of EIS, together with EC simulation, to dynamically characterize rechargeable batteries and fuel cells. Section 2 deals with the basic techniques of impedance measurement and EC simulation. Several key factors during the measurement are discussed. The emphasis is mostly addressed on EC element models and their physical interpretations. The impedance analysis and EC simulation of lead ( $\mathrm{Pb})$-acid batteries and nickel metal-hydride (Ni-MH) batteries are presented in Section 3. And section 4 shows a research case of the EIS application to a proton exchange membrane (PEM) fuel cell stack system. This section also reviews the recent progress in impedance study of novel high temperature PEM fuel cells.

\section{Electrochemical impedance spectroscopy}

The history of impedance spectroscopy (IS) can be dated back to 1880s, when Heaviside initially introduced the concept of "impedance" [10,11] to his research on electromagnetic induction. Later in 1883, Kennelly [12] extended the concept of "impedance" to generalized conductors, and mathematically defined the total impedance of a system, in a complex plane, as the vector sum of its resistance, its inductance-speed ${ }^{1}$, and the reciprocal of its capacity-speed $^{2}$. However, the technique of IS itself did not come out until Nernst [12] employed Wheatstone bridge to measure dielectric constants in 1894.

During the past century, impedance measurement contributed to the characterization of materials and devices, study of electrochemical reaction systems, corrosion of materials, and investigations of power sources. According to different materials and systems it applied to, IS can be classified into two branches [13]. The one following Nernst's initial achievement is called non-electrochemical IS. It applies to dielectric materials, electronically conducting materials, and other complicated materials with combining features [13]. The other branch, newly coming out based on the development of non-electrochemical IS, is named Electrochemical Impedance Spectroscopy (EIS). It focuses on IS applications to ionically conducting materials and electrochemical power sources [13]. The popularity of IS keeps improving especially after the prevailing of electronics and computers. Not only is it capable of dealing with complex processes, reactions, and variables through simple electrical elements, it is also a valid technique for power source diagnosis and system quality controls. This chapter focuses on the applications of EIS to rechargeable batteries and fuel cells.

\footnotetext{
${ }^{1}$ Inductance-speed: The product of angular frequency and inductance, $\omega L$ [12].

${ }^{2}$ Capacity-speed: The product of angular frequency and capacitance, $\omega C$ [12].
} 


\subsection{Measuring techniques}

The EIS measurement is conducted by superimposing an electrical stimulus on the output of the tested electrochemical system and measuring the resulting signal. The impedance of the measuring system is then calculated from the stimulus and its resulting signal by transform functions and Ohm's Law. In this way, the performance of the system under measurement can be studied as a black box, which is described as "feeling an elephant that we cannot see" [14] in Mark Orazem and Tribollet's book. Thus, for an electrochemical system, it is possible to study the properties of its interfaces and materials without taking the system apart. The word "in-situ" generally refers to this type of techniques that characterizes electrochemical systems under operation with the help of voltage, current, and time, distinguishing from " $e x$-situ" techniques which studies individual components departed from electrochemical systems in a non-assembled and non-functional form [15].

Different kinds of electrical stimulus can be used in EIS measurements, including a step function of voltage, a random noise, a single frequency signal, and any other types of stimuli generated by combining the foregoing three ones [16]. With the increasing commercial availability of measuring instruments, the characterization of electrochemical systems generally employs an $a c$ signal (either a small $a c$ voltage or current). In most cases, it is also called "ac impedance".

Several impedance measuring instruments are commercially available, including products from EG\&G Inc., Gamry Instruments, Scribner Associate Inc., and AMETEK (Solartron Analytical and Princeton Applied Research). An instrument set basically consists of a potentiostat, or known as an electrochemical interface, connecting to a frequency response analyzer (FRA). Besides, a complete connection circuit for measurement requires an electronic load. Specifications of different instruments are designed for different scales of measurements. The feasibility and accuracy of measurements are determined by the frequency resolution, frequency accuracy, and bandwidth of instruments and electronic loads. For example, batteries and fuel cells are low impedance systems, usually much lower than $1 \Omega$ (sometimes even down to milliohms) [16]. Their impedance measurement requires a high current and a low frequency bandwidth.

It is worth to noting that the choice of ac signal value have great effect on impedance measurement. The reliability of EIS analysis is based on the assumption that the measured system is linear. It is also important to keep the system in a relatively steady state throughout the measurement to ensure the accuracy of the measured data. The measured impedance data may appear scattered and unregulated if the signal is too weak to excite a measurable perturbation. On the other hand, the signal has to be small enough to keep the measuring system within the range of pseudo-linearity. A larger signal also brings more extra heat that breaks the steady state of the system. The data measured at low frequencies behave more sensitive to the strength of the applied ac signal due to larger impedance at lower frequency [17]. Correspondingly, an appropriate value of the signal should be well picked to ensure the accuracy of the impedance data measured. It is not necessary to determine an exact value for the input signal, however, it has to be controlled in a certain 
range which is neither so small that the output signals are too weak to be measured, nor so large that a great distortion is introduced into measurements. Different signal values can be trailed before measurements to find out a suitable one.

There are two traditional modes for impedance measurements according to different regulating variables: potentiostatic mode and galvanostatic mode. Potentiostatic mode employs a small $a c$ voltage signal with fixed amplitude and measures the resulting $a c$ current. In this mode, the $d c$ voltage is controlled at a certain value that facilitate the control of system linearity. Reversely, a small ac current signal with fixed amplitude is superimposed on the regulated $d c$ current in galvanostatic mode. The resulting $a c$ voltage is measured. Galvanostatic mode provides higher accuracy than potentiostatic mode when measuring low impedance systems because the voltage can be measured more accurately than controlled [18]. This mode is more welcomed where a steady $d c$ current is required during the entire measurement. However, it is difficult to control the resulting $a c$ voltage strictly within the linear range especially at low frequencies.

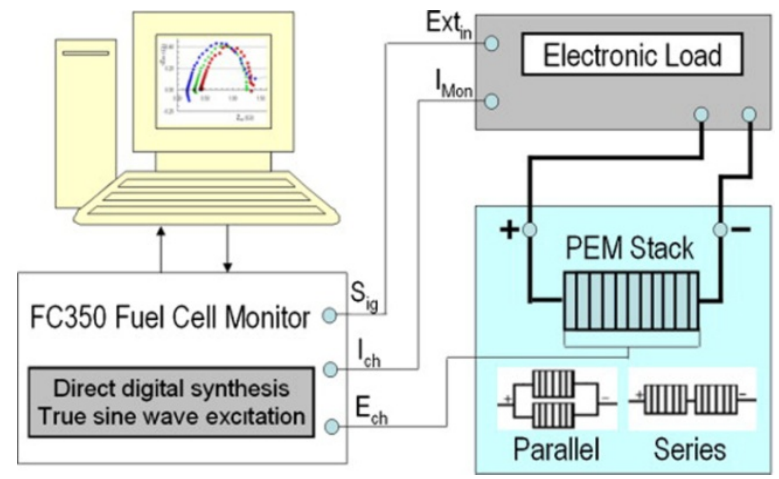

Figure 2. A typical connection diagram for ac impedance measurement conducted on PEM fuel cell stacks: single stack, two stacks in parallel arrangement, and two stacks in series arrangement [19].

A typical connection diagram for ac impedance measurement of a PEM fuel cell stack is presented in Figure 2 [19]. The commercial instrument connected in this measuring system is Gamry FC350 ${ }^{\mathrm{TM}}$ Fuel Cell Monitor. It is featured by its capability to measure impedance at high current levels. The four-terminal connection is commonly used for low impedance measurement (such as batteries and fuel cells) to avoid measurement errors led by the impedance of cables and connections [16]. A novel measuring mode, hybrid mode, is employed instead of galvanostatic mode in order to overcome its drawback. In this mode, the values of a desired voltage perturbation and an estimated system impedance are set before measurements and the $d c$ current is fixed during measurements. The current perturbation at each frequency is adjusted by the desired voltage perturbation and the estimated impedance in order to ensure that the $a c$ voltage does not extend beyond the linear range [17]. The value of ac current signal is calculated from equation (1) [17]. In this equation, $\Delta I_{n}$ is the amplitude of the ac current signal employed to measured the $n^{\text {th }}$ frequency point (at a certain frequency). $\Delta V_{\text {desired }}$ is the desired voltage perturbation set 
before measurements. $\left|Z_{n-1}\right|_{\text {measured }}$ is the magnitude of the system impedance measured at the $(n-1)^{\text {th }}$ frequency point. The impedance value used to obtain the ac current signal for the first frequency point is the estimated impedance value set before measurements [17].

$$
\Delta I_{n}=\frac{\Delta V_{\text {desired }}}{\left|Z_{n-1}\right|_{\text {measured }}}
$$

\subsection{Data analysis and interpretation}

\subsubsection{Data presentation}
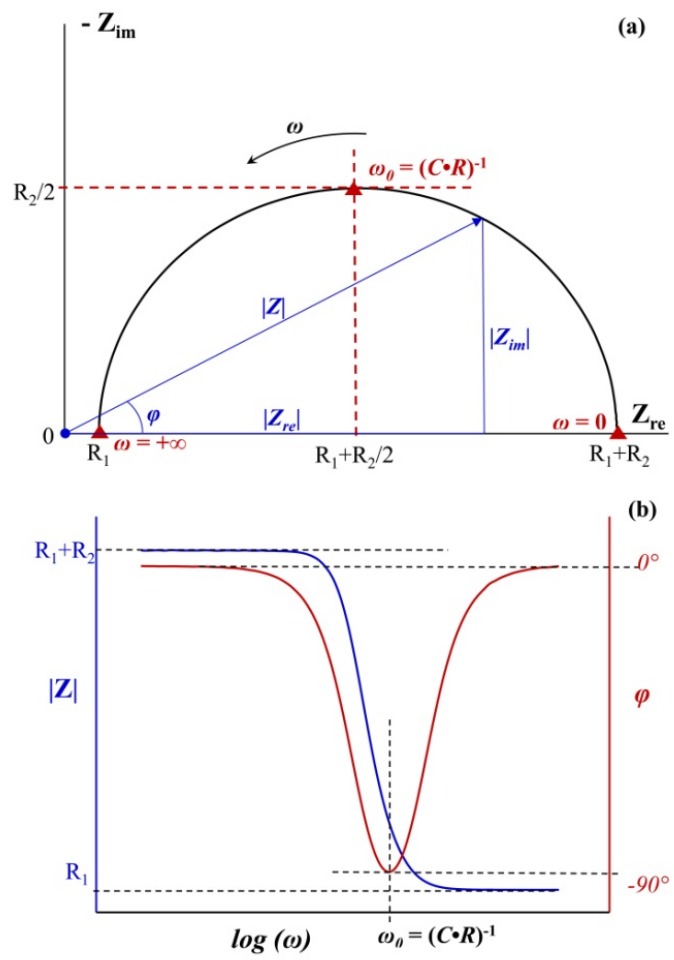

Figure 3. Examples of (a) Nyquist plot and (b) Bode Plot generated by the diagram $\left[R_{1}\left(C R_{2}\right)\right]$.

The two most preferred methods to present impedance data are the Nyquist plot and the Bode plot. Nyquist plot, named after Harry Nyquist, is a polar plot of the transfer function [20]. In some publications, it is also called the complex-plane plot or the Argand plot [16]. An example of Nyquist plot is shown in Figure 3a (plotting method adapted from [20]). This impedance spectrum is a set of continuous complex impedance points produced by the circuit diagram $\left[R_{1}\left(C R_{2}\right)\right]$ over a certain range of frequency (from zero to positive infinite in Figure $3 a$ ). The $x$-axis presents the real component of the impedance points and the $y$-axis presents their negative imaginary component. In this way, the capacitive impedance arcs are flipped to the first quadrant in the plot. As the frequency goes from zero to positive infinite, 
the impedance points move toward the origin of the plane. The impedance value and phase angle of the points can be calculated from the Nyquist plot:

$$
\begin{gathered}
|Z|=\sqrt{\left|Z_{r e}\right|^{2}+\left|Z_{i m}\right|^{2}} \\
\tan \phi=\frac{\left|Z_{i m}\right|}{Z_{r e}}
\end{gathered}
$$

Nyquist plot can provide plenty information of impedance variables but failed to present their frequency dependences. Bode plot, named after Hendrik W. Bode, makes up this inadequacy. It displays the frequency dependence of a linear, time-invariant system, usually shown in logarithmic axis. Figure $3 \mathrm{~b}$ is an example of Bode plot generated by the diagram $\left[R_{1}\left(C R_{2}\right)\right]$. It includes a magnitude plot presenting the magnitude of impedance $(|Z|)$ versus the logarithmic angular frequency $(\log \omega)$, and a phase plot presenting the phase shifts of $a c$ current to ac voltage $(\phi)$ against the logarithmic angular frequency $(\log \omega)$.

\subsubsection{Simulation and interpretation}

There are mainly two methods to acquire models for impedance data interpretation, visually summarized and classified in a flow chart by Macdonald [13]. One mathematically establishes models based on the theory, which puts forward a hypothesis for physical and chemical processes contributed to the impedance. The other one utilizes empirical models, called equivalent circuits (EC). Some researchers also presented a combining method with both of them [22]. The values of certain variables, such as ohmic resistance, were acquired directly from the empirical EC simulation and used as known variables to establish the mathematical model. Whichever employed, the validations of data themselves are essential before simulation. The relations originally published by Kramers (1929) and Kronig (1926) (K-K Transforms) became a simple but effective method for data validation from 1980s, in order to ensure the causality, linearity, and stability of the measured systems [23, 24]. Both the mathematical models and the empirical ECs also have to be validated before data interpretation and system characterization. The fitting programs, generally following the procedures of complex nonlinear least squares (CNLS) fit algorithm (such as LEVM [25] and EQUIVCRT [26]), are employed to validate the derived models by estimating the parameter standard deviation and the goodness of fit [25].

Comparing to mathematical models, deriving an EC model is easier, faster, and more intuitive. An EC diagram is a physical electrical circuit which produces a similar load response to the measured system, derived based on both experiences and theories. The overpotential losses of the testing cell (electrochemical systems) are introduced by the impedances contributed by different physical and chemical processes occurring in the cell (electrochemical system). The impedances of different processes predominate different frequency regions. Thus, they can be identified and mechanistically discriminated by EC simulation according to different process relaxation times. However, the physical interpretation of circuit elements is not straightforward due to the uncertainty of EC diagrams. Different arrangements or combinations of EC elements can produce the same dynamic response when three or more elements are employed in one EC diagram. The only 
solution to overcome this difficulty is acquiring sets of impedance data with different variables and changing conditions.

Three basic EC elements along with their mathematical expressions and physical meanings [27] are summarized in Table 1. $Z$ is the impedance of the elements. $Y$ is the reciprocal of $Z$, called admittance. Generally, resistor $R$, capacitor $C$, and inductor $L$ are three fundamental elements reflecting ideal processes. Figure 4a (plotting method adapted from [27]) sketches out the impedance behavior of the single elements calculated at $R=10 \Omega, C=0.01 \mathrm{~F}$ (from $0.04 \mathrm{~Hz}$ to $100 \mathrm{kHz}$ ), and $L=0.01 \mathrm{H}$ (from $0.1 \mathrm{mHz}$ to $7 \mathrm{kHz}$ ). The impedance of the ideal resistor does not change with frequency. The magnitude of the ideal capacitor's impedance decreases with increasing frequency. Whereas the magnitude of the ideal inductor's impedance increases with increasing frequency.

\begin{tabular}{|c|c|c|c|}
\hline $\begin{array}{c}\text { Element } \\
\text { Symbol }\end{array}$ & $\begin{array}{c}\text { Element } \\
\text { Name }\end{array}$ & $\begin{array}{c}\text { Impedance } \\
\text { Expression }\end{array}$ & Physical Interpretation \\
\hline$R$ & Resistor & $Z_{R}=R$ & $\begin{array}{c}\text { Contributed by energy losses, dissipation of } \\
\text { energy, and potential barrier }\end{array}$ \\
\hline$C$ & Capacitor & $Z_{C}=\frac{1}{j \omega C}$ & $\begin{array}{c}\text { Contributed by accumulations of electrostatic } \\
\text { energy or charge carriers }\end{array}$ \\
\hline$L$ & Inductor & $Z_{L}=j \omega L$ & $\begin{array}{c}\text { Contributed by accumulations of magnetic } \\
\text { energy, self-inductance of current flow, or } \\
\text { charge carrier's movement }\end{array}$ \\
\hline
\end{tabular}

Table 1. The mathematical expressions and physical meanings [27] of ideal EC elements: $R, C$, and $L$.
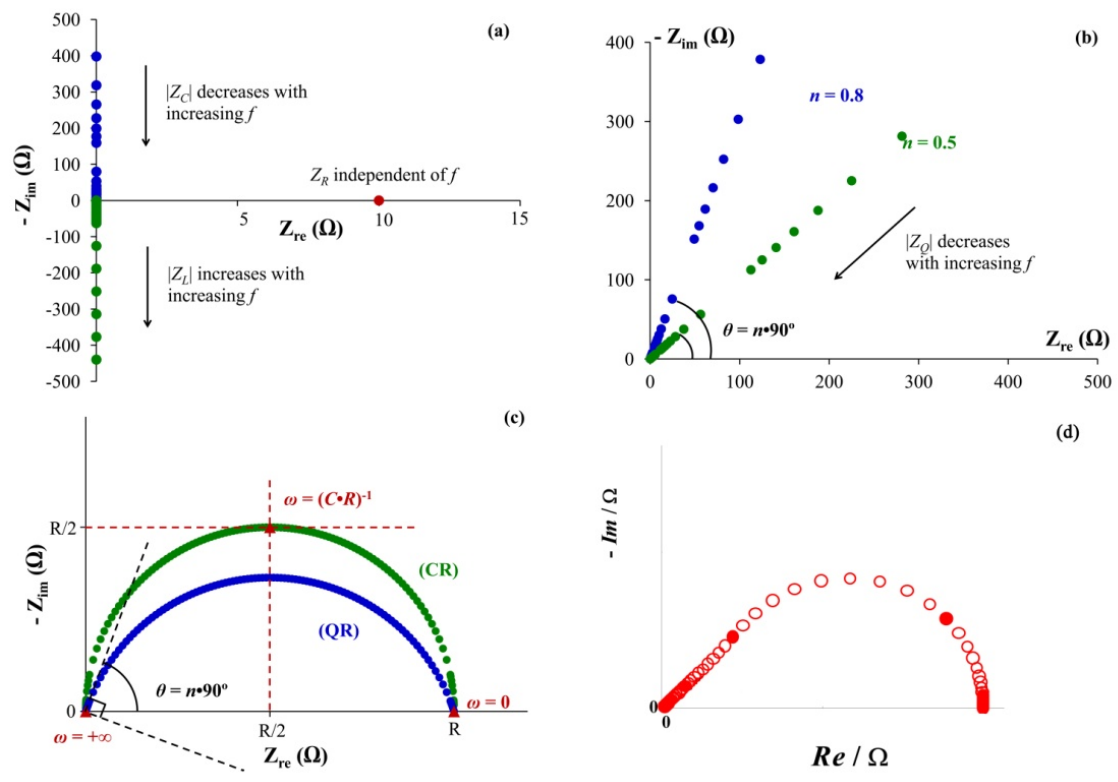

(d)

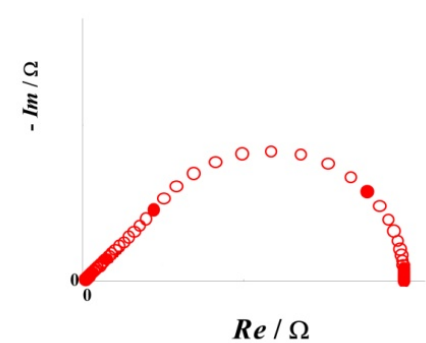

Figure 4. Nyquist plots of (a) $R, C, L,(b) Q,(c)(C R)$ and (QR), and (d) $O$ [27]. 
However, the ideal EC elements only are not able to reflect non-ideal factors in practical cases. A generalized element, constant phase element (CPE) $Q$, was developed to simulate non-ideal processes. $Q$ reflects the exponential distribution of time constants. This non-ideal distribution may be caused by the surface roughness and vary thickness of electrodes, unevenly distributed current, and non-homogeneous reaction rate. In the impedance expression of $Q$ [16] (Table 2), the exponent $n$ reflects the degree of non-ideality. When the value of $n$ in the expression of $Q$ equals to 1,0 , and -1, it can be found that the expression becomes the same as capacitor $C$, resistor $R$, and inductor $L$, respectively. Figure $4 \mathrm{~b}$ (plotting method adapted from [27]) shows two sets of impedance data produced by the expression of $Q$ with $A=100 \mathrm{~F}^{-1}$. They behaves as straight lines across the origin in Nyquist plot. When the value of $n$ decreases from 0.8 to 0.5 , the slope decreases. The angle of incline equals to the time of $n$ and $90^{\circ}$.

The $(C R)$ circuit is one of the basic combinations commonly used in EC simulations. The elements enclosed in parentheses are connected parallel to each other. And the brackets indicate that the elements enclosed are connected in series. For example, $(C R)$ means a pure capacitor $C$ and a pure resistor $R$ are parallel in the connection; while [CR] means a pure capacitor and a pure resistor are connected in series. Figure 4c presents the Nyquist plot of $(C R)$. It is a semi-circle centering at $(R / 2,0)$ with a radius of $R / 2$. As the angular frequency $\omega$ increases from 0 to $\infty$, the summit of the semi-circle is reached when:

$$
\omega=\omega_{0}=\frac{1}{C R}
$$

The $(C R)$ circuit can be employed to simulate an ideal double-layer process. The non-ideal one requires the circuit of $(Q R)$. The element $Q$ replaces $C$ to reflect the non-ideality of an double-layer process. $(Q R)$ behaves as a depressed semi-circle having its center dropped down below the $Z_{\text {real }}$ axis (Figure $4 \mathrm{c}$ ). The degree of the depression is presented by the exponent $n$ of the $Q$ element. The EC diagram $\left[R_{1}\left(C R_{2}\right)\right]$ mentioned previously in Figure 3 is another fundamental combination. Based on the spectrum of $(C R),\left[R_{1}\left(C R_{2}\right)\right]$ shifts horizontally along the positive $Z_{\text {real }}$ axis in Nyquist plot (Figure 3a). The smaller intercept with the $Z_{\text {real }}$ axis equals to the resistor $R_{1}$. And the larger intercept equals to the sum of $R_{1}$ and $R_{2}$. The center of the semi-circle is $\left(R_{1}+R_{2} / 2,0\right)$ and its radius is $R_{2} / 2$.

\begin{tabular}{|c|c|c|}
\hline Element Symbol & Element Name & Impedance Expression \\
\hline$Q$ & $\begin{array}{c}\text { Constant phase element } \\
\text { (CPE) }\end{array}$ & $Z_{Q}=A(j \omega)^{-n}=\frac{1}{Y_{0}(j \omega)^{n}}$ \\
\hline$W$ & Warburg element & $\begin{array}{c}Z_{W}=\frac{\sigma}{\sqrt{\omega}}-j \frac{\sigma}{\sqrt{\omega}} \\
\left|Z_{W}\right|=\sqrt{2} \frac{\sigma}{\sqrt{\omega}}\end{array}$ \\
\hline$O$ & $\begin{array}{l}\text { Finite diffusion element } \\
\text { (FDE) }\end{array}$ & $\begin{array}{c}Z_{O}=\frac{1}{Y_{0} \sqrt{j \omega}} \tanh (B \sqrt{j \omega}) \\
Y_{0}=\frac{(n F)^{2} A}{R_{i g} T}\left(\sum \frac{1}{C_{i} \sqrt{D_{i}}}\right)^{-1} \\
B=\delta / \sqrt{D_{i}}\end{array}$ \\
\hline
\end{tabular}

Table 2. The mathematical expressions of non-ideal EC elements: $Q$ [16], $W$ [29], and $O$ [30]. 
Based on the second Fick's law, Emil Warburg developed expressions for the impedance response of diffusion processes in 1899 [14]. This is now called Warburg diffusion element $(W)$. It is used to simulate an one-dimensional unrestricted diffusion process to a large planar electrode [28]. The mathematical equations for $Z w$ [28] are listed in Table 2. It behaves as a line with unit slope in Nyquist plot, exactly the same as a $Q$ with the exponent $n$ of 0.5 (Figure 4b). Finite diffusion element (FDE) $O$, or sometimes called porous bounded Warburg, was established based on $W$. Its application is extended to a rotating disk electrode (RDE), where diffusion occurs over the Nernst Diffusion Layer (NDL), that is a diffusion layer with finite thickness. The expressions for $Z_{0}$ [30] are listed in Table 2. Figure $4 \mathrm{~d}$ [27] shows a typical Nyquist plot of an $O$ element. Its impedance spectrum presents the same behavior as $W$ at higher frequency region and changes to an arc similar to $(C R)$ at lower frequency region.

Randles circuit $\left[R_{\Omega}\left(C_{d}\left[R_{c t} W\right]\right)\right]$ considers the effect of a diffusion process. It consists of one ohmic resistance $R_{\Omega}$, one parallel $\left(C_{d} R_{c t}\right)$ sub-circuit behaving as a semi-circle in Nyquist plot, and one infinite diffusion element $W$ behaving as a unit slope line at the lowest frequency region. Figure 5 [21] shows a sketch for the impedance spectrum of a Randles circuit. The dash lines illustrate the overlap region of $\left(C_{d} R_{c t}\right)$ and $W$.

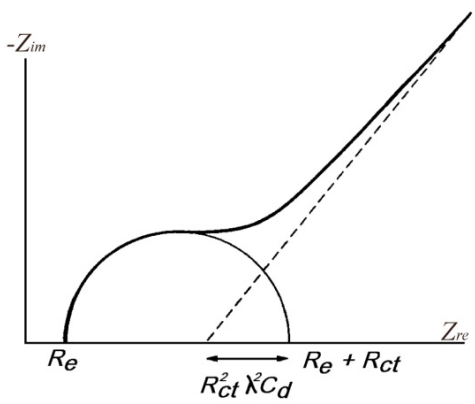

Figure 5. Nyquist plot of Randle's circuit ([21] Courtesy of Solartron Analytical).

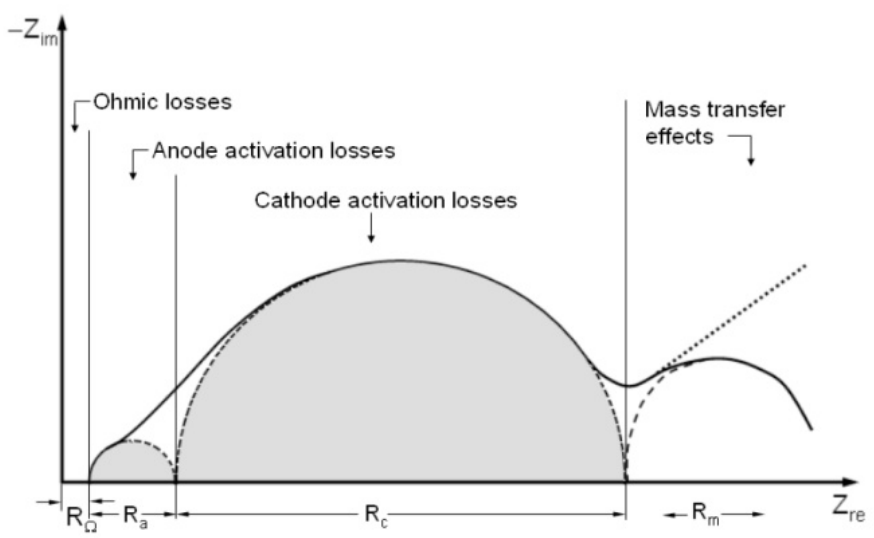

Figure 6. Nyquist plot of a typical EC model for batteries and fuel cells [31]. 
Figure 6 [31] presents the impedance spectra of a typical EC diagram commonly used to simulate batteries and fuel cells. This diagram consists of three time constants. Its total impedance is the sum of the ohmic losses $Z_{\Omega}$, the anode polarization losses $Z_{a}$, the cathode polarization losses $Z_{c}$, and the mass transfer losses $Z_{m}$. The ohmic losses are simulated by one pure resistor $R \Omega$. Its value is represented as the smaller intercept on the real axis. The anode and cathode polarization losses are simulated by a parallel $(C R)$ sub-circuit respectively. Their impedance spectra look like two overlapping semi-circle in Nyquist plot. Some electrochemical systems, like Ni-MH batteries, have strong Warburg behavior in the low frequency region for the mass transfer processes. The diagram can be expressed as $\left[R_{\Omega}\left(C_{a} R_{a}\right)\left(C_{c}\left[R_{c} W\right]\right)\right]$. However, some do not always show this behavior obviously, such as PEM fuel cells. The low frequency arc can be simulated by a parallel $(Q R)$ sub-circuit instead of a pure Warburg element. The diagram is expressed as $\left[R_{\Omega}\left(C_{a} R_{a}\right)\left(C_{c}\left[R_{c}\left(Q_{m} R_{m}\right)\right]\right)\right]$. The Warburg element and sub-circuit $\left(Q_{m} R_{m}\right)$ are connected in series with $R_{c}$ because the mass transfer processes are considered as processes on the cathode side.

\section{EIS applications to rechargeable batteries}

The phrase "electric battery" was innovatively re-defined in late 1740's by Benjamin Franklin [32] when he described a series of his experiments with electricity. However, Franklin's "electric battery" referred to the pile of glass plate capacitors set up in 1748. The production and storage of energy were not achieved until Alessandro Volta designed and built his "crown of cups" and the columnar pile in late 1790s [32]. The Volta pile published in 1800 is generally acknowledged as the first battery because it fulfilled one of the most important functions of batteries: It stored energy in chemicals and converted it into electrical energy by chemical reactions. Although the first reversible system was successfully developed by Johann Ritter in 1802 right after the birth of Volta's pile [33], real rechargeable batteries (also known as secondary batteries) did not come out until Gaston Planté invented the first lead $(\mathrm{Pb})$-acid battery in 1859 [8]. The original concerns to the emergence and development of rechargeable batteries focused on the environmental problems caused by the toxic substances used in batteries. The pollutant substance, generally mercury, used in primary batteries was greatly reduced by decreasing the use of mercury batteries. And the reuse and recycle of rechargeable batteries also moderated the pollutions introduced by itself.

The greater contribution of rechargeable batteries to human beings was explored and well developed with the advancing requirements of grid energy storage. Since rechargeable batteries are feathered by reversible electrochemical reactions, they are able to adapt the energy supplement to the energy demand, that is to store energy in chemicals during valley period and convert energy into electricity during peak period. Having developed for over 150 years, rechargeable batteries have been matured in the commercial applications to automotive starters, electronic products, and all other portable electrical devices daily used. Even EVs requiring light power consumption, such as bicycles and wheelchairs, have been well commercialized. The development and commercialization of pure electric automobiles powered by a build-in rechargeable battery makes it possible to save human lives out from energy crisis and environmental pollutions caused by fossil fuels and combustion engines. 
The development of electric rail network began from the 19th century and prevailed in UK in most of the 20th century [8]. In the past few decades, electric bicycles also predominated in city transportations in China. One of the most challenge issues is the range limitation that an EV can travel with unit battery charge time.

Nelson [34] extensively analyzed and reviewed power requirements for batteries in the HEVs. He recommended for HEV applications that the hybrid driving duty cycle was able to be realistically performed at an operating window between $30 \%$ SoC and $70 \%$ SoC hybrid limits. He also proposed a nominal hybrid operation range of $40-60 \%$ SoC. There is an inefficient charging process above the hybrid limit $(>70 \sim 80 \%)$, and the power output capability is insufficient for start-up, acceleration, or other low-speed driving needs below the hybrid limit $(<20 \sim 30 \%$ SoC).

In general, batteries are expensive and necessary for operating maintenance, and also have limited cycle life. The impedance technique can be applied to dynamic modeling of battery behavior and in-situ diagnosis of battery systems including actual capacity, SoC and SoH [35]. Battery simulation is an important issue for design of different battery applications. It is desired to develop a reliable and easy-to-parameterized battery model. The following two sections present the impedance applications to $\mathrm{Pb}$-acid batteries and $\mathrm{Ni}-\mathrm{MH}$ batteries separately.

\subsection{Pb-acid batteries}

\subsubsection{Characteristics of $\mathrm{Pb}$-acid battery}

As the first type of rechargeable battery, the Pb-acid battery system has features of high-rate discharge ability, suitable specific energy, highly acceptable reliability and toughness. Also, it is commercially beneficial in production and recycle processes because the $\mathrm{Pb}$-acid battery is made primarily from the same low-cost initial material [36]. Recently, the advanced Pbacid battery systems for on-board energy storage have been developed and applied to the HEVs [37-39]. A Pb-acid ultrabattery has been developed within a single battery container by Furkawa et al. [37]. This battery combines features of Pb-acid battery and supercapacitor and is functioned as an integrated hybrid energy storage system. This type of valveregulated $\mathrm{Pb}$-acid battery is designed specifically for high-rate HEV applications at partial state-of-charge (SoC). EnerSys Energy [40] also produced an improved Pb-acid battery, which is called as "Odyssey". The Pb-acid battery delivers much higher cranking power and also retains deep-cycle potentials. Because of the strong needs for development of low-cost energy-saving systems and low-emission vehicles, a few breakthroughs in the lead-acid battery have been made especially in new electrode structure design, rate and deep-cycle performance.

The concentrated $\mathrm{H}_{2} \mathrm{SO}_{4}$ solution is applied in the $\mathrm{Pb}$-acid battery as electrolyte, which is potentially dried out due to the high-temperature working environment. The ionic resistance of the normal operating battery is negligible and makes a small contribution to the series resistance of the battery which depends on the SoC. The unique feature for the 
battery is that the electrode processes involve a dissolution-precipitation mechanism. The electrolyte concentration varies with the change of the battery SoC level due to generation of $\mathrm{SO}_{4}{ }^{2-}$ ions during charge reaction and consumption of $\mathrm{SO}_{4}{ }^{2-}$ ions during discharge process, i.e. both electrodes converted to lead sulfate - double-sulfate reactions. Many challenges for traditional $\mathrm{Pb}$-acid batteries are described as relatively low cycle life (50-500 cycles), especially in electrical vehicle applications, limited energy density, sulfation caused poor charge retention, sulfation during long term storage, and health hazard in designs with antimony and arsenic in grid alloys.

\subsubsection{Pb-acid battery test and impedance data analysis}

The Gamry FC350 ${ }^{\mathrm{TM}}$ system with an electronic load was applied to the battery impedance tests. The measuring circuit was connected as shown in Figure 2 [19], simply replacing the PEM stacks with the batteries. The sinusoidal current signal from the Gamry system, working in the hybrid-impedance mode, modulated the current from the $\mathrm{Pb}$-acid batteries. The hybrid EIS mode was applied for the experiments in order to obtain the impedance data of the rechargeable batteries at various frequencies. The non-linear least squares (NLLS) fitting algorithm was utilized for the impedance spectrum to find the model parameters for best agreement between the simulated impedance spectra and the measured impedance data. The tests were conducted on the Pb-acid batteries by a unique impedance method, i.e. test the batteries at different loads. In-situ test, data analysis, and suitable impedance simulation were performed to develop a wide range design tool or an appropriate model for dynamic applications of $\mathrm{Pb}$-acid batteries for different power reserve demands.

Impedance tests were conducted on three ordinary types of $\mathrm{Pb}$-acid batteries in the experimental work [41]. One (AGN-8) was malfunctioning and taken out from a Toyota car after eight-years' SLI use. The second one (BDU-S) was at rest for ca. eight years, infrequently charged for maintenance requirements. The third battery (CDU-N) was ordered from a local store to substitute the AGN-8 Pb-acid battery. The hybrid EIS mode was utilized in the experiments to examine the EIS behavior at different frequencies. After each measurement, the consumed energy was approximately estimated and charged back in the $\mathrm{Pb}$-acid battery. The battery was considered to be fully charged after overnight charging at a current of less than $1.00 \mathrm{~A}$ with a voltage no more than $13.5 \mathrm{~V}$.

Figure 7 [41] shows the Nyquist plots of three Pb-acid batteries obtained at the load of $5 \mathrm{~A}$. The interesting curve is the one collected from the AGN-8 battery after eight-year's SLI service in vehicle. The battery has been running for eight years and approximately close to its cycle life for the SLI work. The loop curve is clearly different from other Pb-acid batteries near the high frequency side. However, the curves simulated from the circuit diagram $\left[R_{\Omega}\left(R_{1} Q_{1}\right)\left(R_{2} Q_{2}\right) L\right]$ are well agreed with the collected impedance data during the battery test, particularly at $1 \mathrm{~A}$ load of current. At the high frequency side, the change related to the anode surface $\left(\mathrm{Pb} / \mathrm{PbSO}_{4}\right)$ appears to be the major reason for the shape change of the impedance loop. A carbon plate functioned as a capacitor was attached to the negative plate $\left(\mathrm{Pb} / \mathrm{PbSO}_{4}\right)$ [39] in order to improve the anode performance and slow down the electrode 
degradation rate. Not only the burden at the negative electrode is significantly lowered, the rate performance and pulse capability are also considerably improved because of the capacitance behavior from the attached carbon electrode.

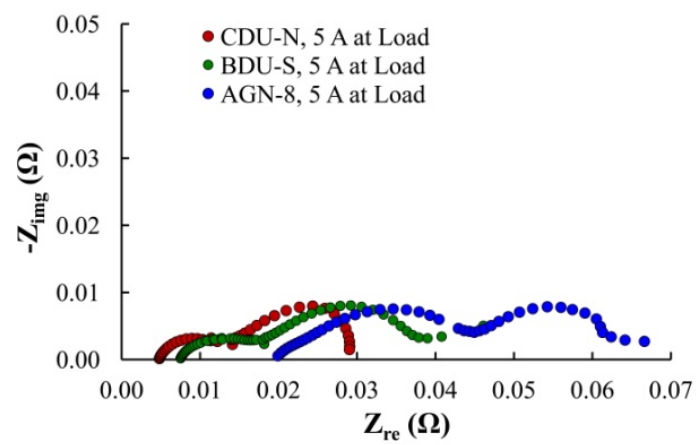

Figure 7. Nyquist plots of three batteries tested at 5A load [41].

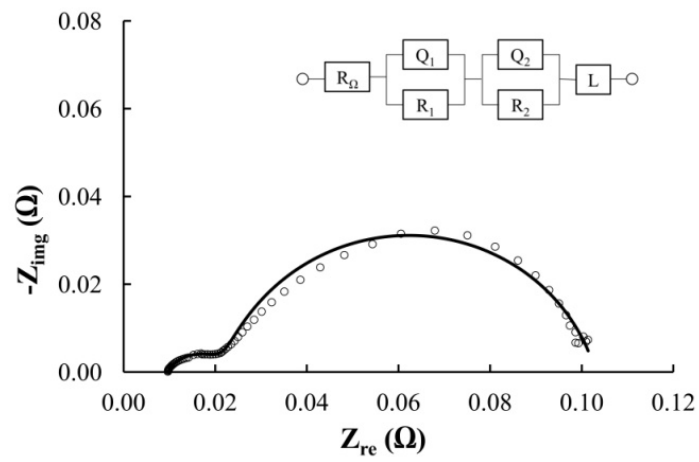

Figure 8. Non-destructive tests of the defective BDU-S battery at $1 \mathrm{~A}$ load [41].

The BDU-S battery was also analyzed based on the EC simulation with the circuit $\left[R_{\Omega}\left(R_{1} Q_{1}\right)\left(R_{2} Q_{2}\right) L\right]$ (Figure 8 [41]). The simulated curve is well fitted to the measured impedance spectra that presents the impedance behavior of the BDU-S battery when it was operated at a load of $1 \mathrm{~A}$ and produced an output voltage of $c a$. $12.17 \mathrm{~V}$ [41]. However, it was no longer capable of operation at the output level of $12 \mathrm{~V}$ due to battery failure. Further diagnostics [41] shown that one cell in the BDU-S battery was suffering degradations. The negative $\left(\mathrm{Pb} / \mathrm{PbSO}_{4}\right)$ electrode was in failure with inadequate charge retention because of sulfation on the anode surface.

\subsubsection{Future performance improvement of rechargeable batteries}

The simulation of the complexity of modern power electronics is very difficult and impedance-based battery models potentially provide useful physical elements and suitable parameters for system dynamic evaluations. The battery performance is considerably non- 
linear and the dynamic performance is determined by numerous parameters such as battery life-time, operating temperature, SoC, and depth-of-discharge (DoD). EIS is a useful tool to get suitable chemical and physical parameters for simulation of battery power systems. The development of high-rate long-life HEV batteries and deep-cycle long-life EV batteries is significantly important for future batteries in vehicle applications. Flat thin-plate structures have been designed and made further improvement for cranking power needs and deepcycle requirement. The amount of lead used in the battery has been greatly reduced using this related technology. It is necessary for future work to examine battery chemistry and advanced electrode processes, estimation of mass transfer limitations, and exploration of the failure mechanisms. Numerous important factors including active material, utilization of active material, current collector, support configuration, electrolyte, separator, and system safeguarding (thermal management and gas recombination) are related to battery performance and operating life-time. For SLI applications nearly more than 100 years, Pbacid batteries have been utilized to provide automobile reserve power requirements. This is because the $\mathrm{Pb}$-acid battery provides the greatest cost/performance ratio among all batteries. The battery designs using advanced concepts and structure enhancements likely produce novel battery power systems with required performance. These efforts potentially stimulate the further technical developments for the deep-cycle and high-rate power needs in energy storage and power reserve applications.

\subsection{Ni-MH batteries}

Unlike the traditional $\mathrm{Ni}-\mathrm{Cd}$ and $\mathrm{Pb}$-acid batteries based on the dissolution-precipitation mechanism with dendrite formation possibility during charge and discharge, the mechanism for a Ni-MH battery is the movement of hydroxide ions between a metal hydride $(\mathrm{MH})$ electrode and nickel hydroxide electrode. This simple mechanism produces a long battery cycle life of more than 1000 cycles, higher power capability, and a dense electrode structure [42]. The battery has natural protection against overcharging and overdischarging with oxygen and hydrogen recombination inside the cell to form water. The overcharge process, over-discharge process, capacity retention, and the in-situ SoC parameter are quite important to the battery cycle life and calendar life time. The improvement of the battery energy storage and conversion efficiencies will significantly increase the overall energy efficiency and prolong the HEV's traveling miles per unit fuel use.

\subsubsection{Ni-MH chemistry and hybrid operating range}

Enhanced energy storage efficiency means less production of $\mathrm{CO}_{2}$ greenhouse gases and lower emissions of $\mathrm{NO}_{x}$ and $\mathrm{SO}_{x}$ for improving acid rain environment. Battery energy storage and fuel efficiency are significantly important for the HEV fuel economics. The charge acceptance, power output capability, and battery cycle-life are key factors for its application in the energy rapid storage considerations. The basic principles and electrochemical reactions occurring in the Ni-MH cell are described as follows [43, 44], 
At the positive electrode,

$$
\mathrm{NiOOH}+\mathrm{H}_{2} \mathrm{O}+e^{-\frac{\text { Discharge } \rightarrow}{\leftarrow \text { Charge }}} \mathrm{Ni}(\mathrm{OH})_{2}+\mathrm{OH}^{-}, E^{0}=0.49 \mathrm{~V} \text { vs. SHE }
$$

At the negative electrode,

$$
\mathrm{MH}+\mathrm{OH}^{-} \frac{\text { Discharge } \rightarrow}{\leftarrow \text { Charge }} \mathrm{M}+\mathrm{H}_{2} \mathrm{O}+e^{-}, E^{0}=-0.83 \mathrm{~V} \text { vs. SHE }
$$

The overall cell reaction is written as

$$
\mathrm{NiOOH}+\mathrm{MH} \frac{\text { Discharge } \rightarrow}{\leftarrow \text { Charge }} \mathrm{Ni}(\mathrm{OH})_{2}+\mathrm{M}, E_{\text {cell }}^{0}=1.32 \mathrm{~V} \text { vs. SHE }
$$

The nickel electrode is thermodynamically unstable in the sealed cell and oxygen-evolution occurs at the electrode as a parallel and competing reaction. The parasitic reaction during charge and overcharge is expressed as

$$
4 \mathrm{OH}^{-} \frac{\text { Charge above } 70 \% \sim 90 \% \mathrm{SoC} \rightarrow}{\text { Overcharge } \rightarrow} 2 \mathrm{H}_{2} \mathrm{O}+\mathrm{O}_{2}+4 e^{-}, E^{0}=-0.41 \mathrm{~V} \text { vs. SHE }
$$

This reaction happens during the battery processes of charge and overcharge. Reaction (8) starts as a parallel side-reaction, competing with the primary charging Reaction (5) at a certain state-of-recharge (SoR, i.e. the actual charge input as percent of the battery-rated capacity). At a higher charging rate, the difference between SoR and SoC may even start earlier due to higher potential and mass transfer limitation of the electrolyte. Hence, the HEV storage application preferably uses the $70 \% \sim 8 \%$ SoC level as the higher hybrid operation limit. However, the nickel-based battery is normally designed that the cell capacity is limited by the positive electrode. The negative to positive capacity ratio varies from 1.5 to 2.0. The evolved oxygen from the positive electrode diffuses to the MH electrode and recombines to form water. Typically, the discharge reserve is approximately $20 \%$ of the positive capacity [43]. The range from 0 to $20 \%$ SoC level is called as deep discharge region. In order to ensure proper power output capability, the HEV energy storage considers the 20 30\% SoC level as the lower hybrid operating limit [34].

\subsubsection{Impedance test and equivalent circuit simulation}

The impedance tests were conducted by the same equipment and measurement connection used for the tests of the $\mathrm{Pb}$-acid batteries. Small amount of the consumed capacity of the Ni$\mathrm{MH}$ battery was estimated and charged back after each test of impedance measurement. After the Ni-MH battery was prepared for impedance measurement at another SoR, the Gamry impedance system together with an electronic load, operating in hybrid impedance mode, modulated the current information from the working battery at load. At the same time, the current signal at the electronic load was sent back for the computer data management. The Gamry system collects these measured data and creates the data files for further impedance data processing and circuit simulation. 
The Ni-MH battery was charged to a certain level of SoR at a $0.2 \mathrm{C}$ rate and then conducted impedance tests with an electronic load. The battery capacity was measured as $3.7 \mathrm{Ahr}$ at 0.2 $\mathrm{C}$ rate and impedance data were collected in condition of $0.37 \mathrm{~mA}$ load and $5 \mathrm{mV}$ ac voltage at $c a .50 \%$ SoR. The ac impedance data were analyzed and the Nyquist plot of the Ni-MH battery is shown in Figure 9. The simulated curve via an EC model of $\left[R\left(Q_{a} R_{a}\right)\left(Q_{c}\left[R_{c} Q_{m}\right]\right)\right]$ is well agreed with impedance data in the above Nyquist plot. This EC model is a modification based on the one illustrated in Figure 6. CPEs are used to replacing the pure capacitors and the Warburg element in order to take in account the non-ideal effects. In considering of energy efficiency, inefficient charge, capacity retention rate, power output needs, battery cycle-life, as well as Nelson's valuable work, the Ni-MH battery for on-board energy storage is preferred to work at $50 \pm 10 \%$ SoC with an operating limitation of $50 \pm 20 \%$ SoC. It is easy to accurately measure various battery parameters during the battery off-board break, but the challenge is to dynamically determine the current SoC level for on-board energy storage and in-time energy release when the battery pack is being operated inside a moving vehicle. Energy efficiency is important for HEV fuel economics and further improvement of system efficiency means less greenhouse gases and lower emissions. Although the ultra-capacitor is an alternative solution to the burst energy storage, the battery with a suitable capacitance behavior is still an ideal solution in considering of the total cost of the energy storage and conversion system.

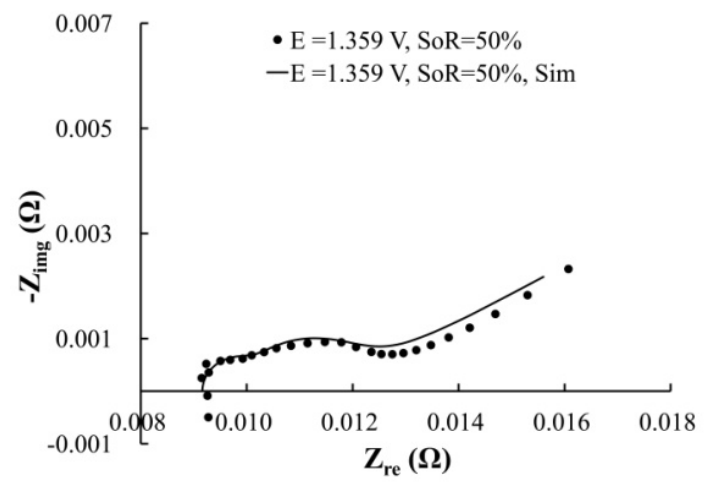

Figure 9. Simulated curve via an EC model of $\left[R\left(Q_{a} R_{a}\right)\left(Q_{c}\left[R_{c} Q_{m}\right]\right)\right]$ well agreed with impedance data in the Nyquist plot of the Ni-MH battery.

\section{EIS applications to proton exchange membrane fuel cells}

Both the energy quick consumption and alternative fuel development require further improvement of energy efficiency for lowering costs and reducing emissions. The zero exhaust is the most attractive advantage of fuel cells over other energy conversion technologies. In comparison with batteries, fuel cells require a continuous fuel supplement as long as they convert chemical energy to electricity. The first fuel cell can be traced back to William Grove's "gaseous voltaic battery" developed in 1839 [45]. This prototype successfully proved that the reaction of hydrogen and oxygen could produce electricity. 
After many attempts at improving the "gas battery" by several investigators, Ludwig Mond and Carl Langer significantly achieved the practical one. Their "new gas battery" published in 1889 [46] was considered as the prototype of current fuel cells. However, it was not until 1960s when the commercial application of a fuel cell was realized for the first time in NASA's Gemini program [47]. General Motors produced their hydrogen powered fuel cell vehicle in 1967 [47], inspiring the research and development of fuel cells to be commercially applied to automotives and replace combustion engines.

Generally, fuel cells are classified into five main types based on different electrolyte [16]. Alkaline fuel cell (AFC) utilizes aqueous alkaline solutions as electrolyte. It is now able to operate below $100^{\circ} \mathrm{C}$. Proton exchange membrane (PEM) fuel cell is featured by the solid polymer electrolyte. Its low temperature operation and high energy conversion efficient make it become one of the most promising solution to combustion engines. Phosphoric acid fuel cell (PAFC) uses concentrated or liquid phosphoric acid $\left(\mathrm{H}_{3} \mathrm{PO}_{4}\right.$, abbreviated to PA) as electrolyte and operates at around $200^{\circ} \mathrm{C}$. Molten carbonate fuel cell (MCFC) and solid oxide fuel cell (SOFC), operating at extremely high temperature, overcome the poisoning issues of the other three types and reduce operation costs. An electrical efficiency of $60 \%$ were reported to be achieved in 2009 by a natural gas powered SOFC device (Ceramic Fuel Cells Limited).

Fuel cell systems produce much higher efficiency than combustion engines; however, two major challenges, high cost and low reliability, have to be overcome to implement its successful commercialization. Properly designed fuel cell systems can be a reliable and durable method to provide high efficient and environmentally friendly power sources for many applications, including global transportations, portable devices, and residential backups. Integrated systems, consisting with the subsystems of fuel processor, fuel cell, power electronics, and thermal management, can successfully fulfill the production of both electricity and heat simultaneously from the same power source, called combined heat and power (CHP) [15].

Comparing to battery investigations, EIS dedicated more contributions to the development and diagnostics of fuel cells. Impedance measurement, analysis and EC simulation can be conducted to investigate component fabrications, interfacial processes, transfer mechanisms and cell degradations of several types of fuel cells. Current fuel cell investigations are mainly focus on cell degradation, recoverable poisoning, state of MEA health, and stability of long-term operation. The EC models, plausible explanations, and remaining problems of conventional PEM fuel cells and high temperature PEM fuel cells will be reviewed and presented in this section.

\subsection{Conventional proton exchange membrane fuel cells}

\subsubsection{Impedance measurement}

The Ballard Nexa ${ }^{\mathrm{TM}}$ fuel cell system [19, 30, 48] was connected to the measuring circuit (Figure 2 [19]). The power module contains one PEM stack consisting of 47 single planar fuel 
cells, each with an active area of $c a .122 \mathrm{~cm}^{2}$. It provides an unregulated $d c$ power output of $1200 \mathrm{~W}$ at nominal output voltage of $26 \mathrm{Vdc}$. The rated output current of the stack reaches $44 \mathrm{~A}$ and its open circuit voltage normally rises up to $41 \mathrm{~V}$. A controller board is embedded in the module to facilitate the automated stack operation. Measurement of the stack without the embedded controller board were accomplished by electrically isolating the PEM stack from the controller subsystem.

The tests were conducted on three PEM stacks numbered \#308, \#515, and \#881, identical to each other. There were totally five sets of impedance tests of the stacks published with different scales listed below $[19,30,48]$. The impedance data of the stacks were collected at different current levels without embedded system controller in most of the tests. However, several sets of impedance data were collected from the stacks together with the embedded controller board. The Gamry FC $350^{\mathrm{TM}}$ fuel cell monitor connecting to a TDI-Dynaload ${ }^{\circledR}$ RBL488 programmable load was employed to obtain impedance data. Different small ac signals were chosen according to different scales of the tests, ensuring the accuracy of the data without scattering.

1. Single cell tests

The single planar fuel cells in the stack \#308 were tested separately at the temperature of $26^{\circ} \mathrm{C}$ under varying current loads of $0.2 \mathrm{Adc}, 0.5 \mathrm{Adc}$, and $1.0 \mathrm{Adc}$, without the embedded system controller [30]. The single cells are numbered from the anode side to the cathode side. An ac voltage signal changed from $10 \mathrm{mV}$ to $20 \mathrm{mV}$ was set as the desired voltage perturbation in hybrid mode, according to different system current loads. The impedance data were collected from the single cells numbered \#10, \#15, \#25, \#31, and \#47. Three sets of them are shown in Figure 10 [30]. The impedance behavior of the $47^{\text {th }}$ cell in the stack obviously differs from the impedance behaviors of others. It has the lowest ohmic resistance because the humidified air inlet increases the cell humidity. However, the observable mass transport losses are caused by impurity build-up. For each single cell, no significant difference in ohmic resistance is observed when the current changes. However, cells closer to the anode side bear higher resistance due to less humidity.

\section{Group cell tests}

Four fuel cell groups consisting with different number of single cells $(12,24,36$, and 47 cells respectively) in the stack $\# 308$ were tested at the temperature of $26^{\circ} \mathrm{C}$ and a current load of 0.2 Adc without the embedded system controller [30]. A desired ac voltage signal of $10 \mathrm{mV}$ was set for the cell groups in hybrid mode. There are no significant changes between the ohmic resistances of each group; however, the polarization resistance, which dominates the cell impedance, increases proportional with the increase of cell numbers.

3. Single stack test

The single stack tests were conducted individually on the stack \#308 [30], \#515, and \#881 [19, 48]. Impedance data of the stack $\# 308$ were measured with and without the embedded system controller at relatively steady state under each current load using an ac current signal 
of $500 \mathrm{~mA}$ in galvanostatic mode over a frequency range from $10 \mu \mathrm{Hz}$ to $20 \mathrm{kHz}$. The \#515 and \#881 PEM stacks were measured at varying $d c$ current loads with a desired $a c$ voltage signal of $150 \mathrm{mV}$ in hybrid mode over a frequency range from $10 \mathrm{mHz}$ to $10 \mathrm{kHz}$, both with (Figure 11a [19]) and without (Figure 11b [19]) the embedded system. Though the impedance collected with the embedded system is larger than the one without, both sets of impedance spectra have the same behavior and change tendency.

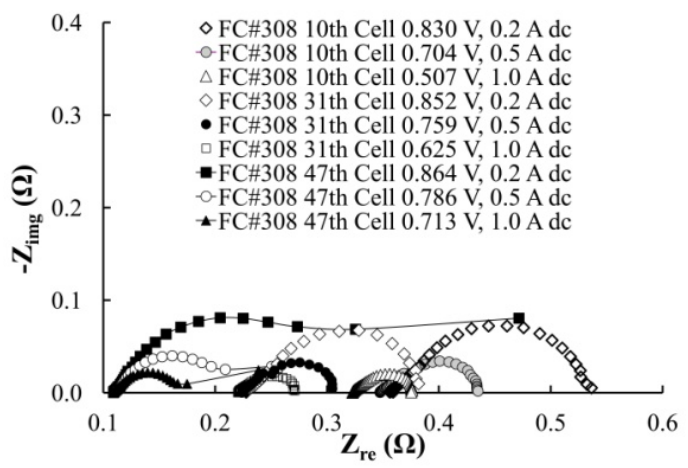

Figure 10. Nyquist plots of single cells numbered \#10, \#31, and \#47 of the PEM fuel cell stack \#308 in the NexaTM PEM system [30].
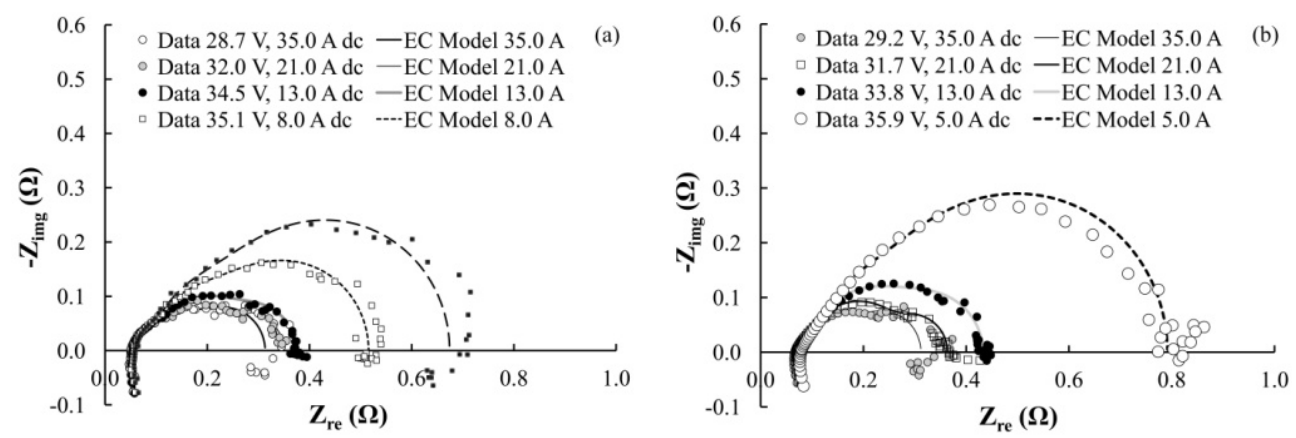

Figure 11. Nyquist plots of the PEM fuel cell stack \#515 in NexaTM PEM system. (a) The PEM fuel cell stack is equipped with embedded controller, compressor, and other electronic devices; (b) The PEM fuel cell stack is running while its controller board and other electronic devices uses an external power source [19].

4. Group stack tests - two stacks in series

The PEM stack $\# 515$ and $\# 881$ were operated in series as one power source [19]. The impedance of the stack group with the embedded system controllers was measured with a desired voltage perturbation of $150 \mathrm{mV}$ in hybrid mode. The current of $5 \mathrm{Adc}, 10 \mathrm{Adc}, 15$ Adc, and 30 Adc were loaded to the whole power system. The impedance spectra present the similar behavior as the single stack (Figure 12a [19]). 


\section{Group stack tests - two stacks in parallel}

The PEM stack \#515 and \#881 were operated in parallel as one power source $[19,48]$. The impedance of the stack group was measured following the same procedures as the measurement of the series stack group. A desired ac voltage of $150 \mathrm{mV}$ was employed in hybrid mode. The current of 10 Adc, 21 Adc, 30 Adc, 40 Adc, and 60 Adc were loaded to the whole power system. The impedance behavior and variation tendency are consistent with the data set collected from the single stacks and the series stack group (Figure 12b [19]). However, the impedance of the parallel stack group is reduced to about one quarter of the series stack group. Thus, the parallel connection is preferred for commercial applications.
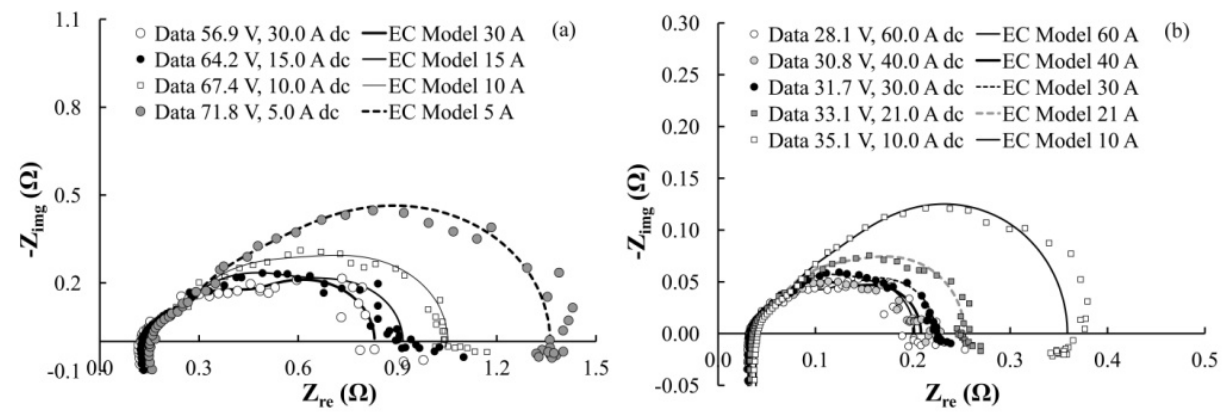

Figure 12. Nyquist plots of the PEM fuel cell stacks \#515 and \#881 (a) in series and (b) in parallel operation embedded with system controller, compressor, and other electronic devices [19].

\subsubsection{EC simulation}

A three time constant diagram, $\left[R_{\Omega}\left(R_{a} C_{a}\right)\left(R_{c} C_{c}\right)\left(R_{m} C_{m}\right) L\right]$, was applied to the sets of impedance data measured from the single PEM fuel cell stacks (\#515 and \#881 separately) and the two stack groups (\#515 and \#881 in parallel and in series). The Nyquist plots of measured impedance data and the simulation curves calculated from the EC model are shown in Figures 9, 10, and 11. It is possible to determine the bipolar plate contact and membrane electrolyte resistance from ohmic resistance $R_{\Omega}$ by switching the embedded control system to an external power supply and subtracting the wiring and contacting resistance. The following three parallel $(R C)$ sub-circuits break down the polarization impedance into different parts contributed by different processes, including the anode activation process $\left(R_{a} C_{a}\right)$, the cathode activation process $\left(R_{c} C_{c}\right)$, and the gas diffusion process $\left(R_{m} C_{m}\right)$. The catalyst loading level at the cathode side is two to three times higher than that at the anode side [49]. Thus, the cathode activation impedance is determined to be the large arc at middle frequency region, the resistance calculated from the EC model of which is about two to three times larger than the one ascribed to the anode activation impedance dominating the high frequency region. The stack impedance is mainly dominated by the cathode activation impedance, but with the increase of current loads, its contribution significantly decreases. Meanwhile, the contribution of the gas diffusion impedance greatly increases with the increasing current load, even up to almost half of the total stack impedance. 
It can be observed that at high frequency region (the smaller semi-circles closer to the origin of the coordination) the simulated curves are well fitted to the measured data. On the other hand, the simulated curves at lower frequency region (the large semi-circle dominating the stack impedance) derivate from the measured data. The $\left(R_{m} C_{m}\right)$ sub-circuit may not be accurate enough to simulate the impedance arc at low frequency region. Since it is determined to be a finite gas diffusion process, an $O$ element should be much more suitable for the simulation. From the aspect of its physical meaning, an $O$ element also facilitates data interpretation. The $\left(R_{m} C_{m}\right)$ sub-circuit was kept other than being substituted by an $O$ element to facilitate the following PSpice simulation. Although the impedance spectra simulated by the EC model slightly deviated from the impedance of the real PEM system, the pulse load test simulated in PSpice by this EC model presented acceptable results [19]. This preliminary test provided a realistic method for further design, operation, and control of an integrated system.

\subsection{High temperature proton exchange membrane fuel cells}

\subsubsection{High temperature membranes}

The performance of a conventional PEM fuel cell is limited by its operating temperature. The traditional perfluorosulfonic acid (PFSA) membrane exhibits great conductivity, excellent thermal and chemical stability, and considerable economic efficiency, but suffers from severe degradations at the temperature higher than $100^{\circ} \mathrm{C}$. Thus, it is desired to develop alternatives to PFSA membranes to overcome this drawback.

Generally, the alternative membranes can be classified into three groups according to different methods of membrane fabrications. One is to attach charged units to a conventional polymer [50]. Most attentions to this type of alternative membranes have been paid to sulfonated polymer membranes and their composites [51]. Another group of membranes is named inorganic-organic composites or hybrid, which are fabricated by incorporating a polymer matrix with inorganic compounds [50]. Modified PFSA membranes [51], especially modified Nafion membranes [52, 53], are highly recommended due to competitive advantages of PFSA membranes in PEM fuel cell applications over others. Modifications of PFSA membrane are mainly focused on the proton conductivity at higher temperature, water uptake and retain at higher temperature, low humidification operations, and mechanical stability at higher temperature.

The third group of alternative membranes is acid-base polymer membranes. This type of membranes is complexes fabricated by doping strong acids or polymeric acids in conventional polymers [50]. So far, phosphoric acid $\left(\mathrm{H}_{3} \mathrm{PO}_{4}\right.$, abbreviated to PA) doped polybenzimidazole (PBI) has been found to be one of the most commercially promising materials for PEM fuel cell operating at temperature higher than $100^{\circ} \mathrm{C}$. The advantages of PBI over other polymers, including low cost [54], high glass transition temperature [55], excellent textile fiber properties [56], and great thermal stability [57], promised it to be an excellent polymer for membrane fabrications. One of the most significant advantages of a PA doped PBI membrane over a PFSA based membrane is that its conductivity no longer 
relies on the water content due to its unique proton conduction mechanism [50, 58-60], but strongly depends on the PA doping level [50, 61-63] and the operating temperature [50,63, 64].

\subsubsection{Impedance study}

There are only limited studies of EIS applications to high temperature PEM fuel cells. Impedance measurement was pioneered to study the electrical conductivity of PBI-based films at the end of 1990s. Fontanella and his co-workers [65] utilized impedance measurement to study the conductivity of PA doped PBI films at the temperatures below $100^{\circ} \mathrm{C}$ at a pressure up to $0.25 \mathrm{GPa}$. Soon after that, Bouchet and Siebert [61] published their work of measuring the conductivity of acid doped PBI films with the help of impedance measurement. However, in these works, impedance measurement was utilized only as an auxiliary method.

EIS was not applied to a membrane electrode assembly (MEA) or a fully constructed PEM fuel cell based on high temperature membrane until 2005. Xu [66] employed impedance analysis to study the effect of relative humidity $(\mathrm{RH})$ on oxygen reduction reaction (ORR) kinetics for a high temperature PEM fuel cell manufactured from Nafion-Teflonphosphotungstic acid (NTPA) membranes. Almost at the same time, Ramani [67] published their impedance measurement to a PEM fuel cell based on PA doped Nafion membrane at $120^{\circ} \mathrm{C}$ and $35 \% \mathrm{RH}$.

Several EIS studies on PA-PBI based high temperature PEM fuel cells emerged from 2006 [68-72]. Jalani and his co-workers [68] published their impedance analysis of a single cell assembly, named Celtec ${ }^{\circledR}$-P series 1000 MEA (BASF Fuel Cell). Qi and his group [72] applied EIS to study the performance and degradation of a PA-PBI based PEM fuel cell at $180^{\circ} \mathrm{C}$ under a current density of $0.2 \mathrm{~A} \mathrm{~cm}^{-2}$. However, both groups did not perform EC simulations of the cell impedance. At the same time, a more completed EIS application was published by Jingwei $\mathrm{Hu}$ and his co-workers [22, 69-71], which included a series work of impedance measurement and analysis, EC simulations, and degradation tests of cell performance.

The published applications of EIS on high temperature PEM fuel cells, although limited, present different measurement results one from another. Several different EC diagrams were proposed to interpret measured impedance data. An ohmic resistance, introduced by cell components (electrodes, membranes, gas diffusion layers, and other supporting plates) and connections, and a wiring inductance were involved in impedance analysis of all published works. Main differences exist in the analysis and interpretation of polarization impedance. Cells tested with different configurations and operating conditions perform differently from each other; however, they should behave certain characteristics in common, especially the cells with the same type of membrane. The EIS applications to high temperature PEM fuel cells based on PA doped PBI membranes will be summarized and discussed in the following section. The emphases are placed on EC simulations and data interpretations. 


\subsubsection{EC simulation and data interpretation}

So far, up to three arcs have been reported in Nyquist plots of measured impedance spectra, but they were not well separated in all cases. One arc overlapped with its neighboring ones when they shifted to a similar frequency range with the change of cell operating conditions. In some circumstances, one arc decreased to be negligible. The processes involved in data interpretation mainly include charge transfer process, mass transfer process, and gas diffusion process. However, some groups observing two impedance arcs in Nyquist plot preferred to classify the impedance arcs into anodic and cathodic processes [73-78].

1. Ohmic resistance

Ohmic resistance, $R_{\Omega}$, is the sum of resistances of membranes, electrodes, catalyst layers, and gas diffusion layers, contact resistance, and any other resistances introduced by the hardware connected to the measuring circuit, such as wires, heaters, blowers, and controller boards. Although it is difficult to break down the total ohmic resistance according to different contributions, its change with varying operating conditions of cells mainly reflects the conductivity of membranes. Thus, the proton conductivity mechanism of PA doped PBI membranes can be studied with the help of ohmic resistance.

$R_{\Omega}$ was reported as a set of scattered numbers with increasing current density in Jalani's work [68]; however, a trend of decline was still observable from the published data. Later, it was confirmed in many other experiments that $R \Omega$ decreases with increasing current density [77, 79-82]. Following Zhang's theory [79], it was accepted that the decrease of $R_{\Omega}$ was resulted from an increase in the proton conductivity of the membrane due to higher water productivity at higher current density. However, Zhang [79] also expected a constant level of $R \Omega$ at a current density larger than $1.0 \mathrm{~A} \mathrm{~cm}^{-2}$ because of a constant water uptake of the membrane balanced between produced and purged water. This constant level was observed in Andreasen's experiments both on a $1 \mathrm{~kW}$ cell stack [78] and a single cell MEA [83] even at a current density lower than $1.0 \mathrm{~A} \mathrm{~cm}^{-2}$.

The effect of operating temperature on $R_{\Omega}$ is more complicated than current density. And lots of attentions were paid to it since the activation behavior closely relates to the proton conductivity mechanism of membranes. Some reported that $R_{\Omega}$ decreased with increasing temperature $[77,79,83]$. The proton hopping mechanism proposed by Bouchet $[60,63]$ was applied to explain this thermal effect [79]. The membrane conductivity $\sigma$ based on this mechanism is expressed as [50, 61]:

$$
\sigma=\sigma^{0} \exp \left(\frac{-E_{a}}{R T}\right)=\frac{A}{T} \exp \left(\frac{-E_{a}}{R T}\right)
$$

where $\sigma^{0}$ and $A$ are pre-exponential factors, $E_{a}$ is the activation energy, and $R$ is the ideal gas constant.

But, inconsistent with these results, many other researchers reported an increase of $R \Omega$ with increasing temperature when the temperature went higher than around $140^{\circ} \mathrm{C}[73,80,82]$. 


\section{High frequency (HF) impedance arc}

This arc appears right after the wiring inductive loop as frequency decreases in Nyquist plot. And generally it is quite a small semi-circle comparing to the following impedance arcs. It dominates the region of frequency from above $100 \mathrm{~Hz}$ up to $1000 \mathrm{~Hz}$ [68, 78, 79, 81-84], or even higher. The effects of temperature $[79,82]$ and current density $[81,82]$ on this impedance arc are observable but not as significant as on other impedance arcs dominating lower frequency regions. The resistance of this HF impedance arc decreases with increasing current densities, and its time constant decreases with increasing temperature. The latter can be observed in Nyquist plot as the impedance arc shifts toward higher frequency, or "shrinks". Kinetically, this phenomenon can be explained as the process occurring faster at higher temperature.

It was validated and discussed in many published works that this HF impedance arc is contributed by charge transfer processes. Its impedance is generally simulated by the $\left(R_{c t} C_{d}\right)$ sub-circuit in EC models. The $R_{c t}$ refers to charge transfer resistance and the $C_{d}$ refers to double-layer capacitance introduced by the charge accumulation and separation in the interface of electrode-electrolyte. In some cases, the double layer capacitor may be substituted by a CPE to reflect the non-ideal characteristics of the interface. Many researchers preferred to ascribe this HF arc to the charge transfer process occurring on the anode, that was the charge transfer process involved in hydrogen oxidation reaction (HOR) $[73,77,78,80]$. Some other groups stated that the charge transfer processes of both HOR and ORR contributed to this HF impedance arc; however, the contribution of HOR was negligible at low current density $[79,82]$.

3. Middle frequency (MF) impedance arc

This arc is contributed by the most dominating process occurring in the cell. It usually appears as the largest semi-circle in Nyquist plot and spans from $100 \mathrm{~Hz}$ to $1 \mathrm{~Hz}[68,78,79$, 81-84]. A consistent interpretation proposed for this arc were widely accepted in published cases that an activation process related to ORR contributed to this polarization loss.

In some cases, only one impedance arc was observed in Nyquist plot $[22,69-71,85,86]$. The low frequency (LF) arc does not perform significant contribution to the total impedance at all circumstances (discussed later in the part of "LF impedance arc"). And sometimes, as mentioned in the discussion of HF arc, the HF arc shrinks to be hardly noticed. Thus, the only arc observed can be explained as mass transfer processes. In this case, the HF arc actually merges with the MF arc and the total impedance appears as one arc.

4. Low frequency (LF) impedance arc

This arc only appears in some certain cases when the contributions of concentration processes to cell impedance are comparably significant. Generally, it dominates frequency region below $1 \mathrm{~Hz}$ down to around $0.1 \mathrm{~Hz}$ [68, 78, 79, 81-84]. The impedance of this arc strongly depends on the compositions of cathode inlet gas, generally consisting of air, oxygen, or a mixture of them. The LF arc enlarges with the increase of current loads and dominates the total impedance at high current loads instead of the MF arc. Studies on oxygen stoichiometry can provided further information for the study of diffusion processes. 


\section{Conclusions}

This chapter emphasizes the existing necessities for the improvement and development of energy storage and conversion systems and highlights the competence of Electrochemical Impedance Spectroscopy (EIS) to dynamically characterize electrochemical systems. As the background, this chapter briefly provided fundamental knowledge of impedance measurement and data interpretation. The EIS applications are mainly focused on $\mathrm{Pb}$-acid batteries, Ni-MH batteries, conventional proton exchange membrane (PEM) fuel cells, and high temperature PEM fuel cells based on phosphoric acid $\left(\mathrm{H}_{3} \mathrm{PO}_{4}\right.$, abbreviated to PA) doped polybenzimidazole (PBI) membranes. For the rechargeable batteries and the conventional PEM fuel cells, investigation examples are presented with discussions on research challenges and further development. The high temperature PEM fuel cell is a freshly emergent research area. There are obvious differences between the behavior and variation tendency of impedance data collected from different systems. Several equivalent circuit (EC) diagrams and their physical interpretations were proposed for different high temperature PEM fuel cells. However, more experiments and impedance data are required to develop a consistent, validated, and generally accepted theory. Developed for over a hundred years, EIS will continuously contribute to the characterization, diagnosis, quality control, and further advanced areas of energy storage and conversion systems for energy economic considerations.

\section{Author details}

Ying Zhu, Wenhua H. Zhu and Bruce J. Tatarchuk

Center for Microfibrous Materials

Department of Chemical Engineering

Auburn University, Auburn, AL, 36849, USA

\section{Acknowledgement}

This work was performed under a U.S. Army contract at Auburn University (W56HZV-05C0686) administered through TARDEC. The authors would like to thank members from the Center for Microfibrous Materials for their assistance and contribution to this work.

\section{References}

[1] Tatarchuk BJ, Yang H, Kalluri R, Cahela DR, inventors. Microfibrous Media for Optimizing and Controlling Highly Exothermic and Highly Endothermic Reactions/Processes. 2011; Patent No: WO2011/057150A1.

[2] Sheng M, Cahela DR, Yang H, Tatarchuk BJ. Application of Microfiber Entrapped Catalyst in Fischer-Tropsch Synthesis. AIChE Annual Meeting, 2009; Nashville, TN, United States.

\footnotetext{
${ }^{*}$ Corresponding Author
} 
[3] Sheng M, Yang H, Cahela DR, Tatarchuk BJ. Novel Catalyst Structures with Enhanced Heat Transfer Characteristics. Journal of Catalysis 2011; 281(2):254-262.

[4] Chew TL, Bhatia S. Catalytic Processes towards the Production of Biofuels in a Palm Oil and Oil Palm Biomass-Based Biorefinery. Bioresource Technology 2008;99(17):79117922.

[5] Chen Y. Development and Application of Co-Culture for Ethanol Production by CoFermentation of Glucose and Xylose: A Systematic Review. Journal of Industrial Microbiology \& Biotechnology 2011;38(5):581-597.

[6] Demirbas A. Hydrogen Production from Carbonaceous Solid Wastes by Steam Reforming. Energy Sources Part A - Recovery Utilization and Environmental Effects. 2008;30(10):924-931.

[7] Yuan L-X, Wang Z-X, Dong T, Kan T, Zhu X-F, Li Q-X. Hydrogen and Liquid Bio-fuel Generated from Biomass. Journal of University of Science and Technology of China. 2008;38(6):6.

[8] Mantell CL. Batteries and Energy Systems: McGraw-Hill; 1983.

[9] Prokhorov DV. Toyota Prius HEV Neurocontrol and Diagnostics. Neural Networks. 2008;21(2-3):458-465.

[10] Heaviside O. The Induction of Currents in Cores. Electrical Papers. 1. New York: Macmillan and Co.; 1894. p. 353-415.

[11] Heaviside O. Electromagnetic Induction and Its Propagation (2nd Half). Electrical Papers. 2. New York: Macmillan and Co.; 1894. p. 39-154.

[12] Kennelly AE. Impedance. The 76th meeting of the American Institute of Electrical Engineers, 1893; New York, NY, United States; p. 172-232.

[13] Macdonald JR. Impedance Spectroscopy. Annals of Biomedical Engineering. 1992;20(3):289-305.

[14] Orazem ME, Tribollet B. Electrochemical Impedance Spectroscopy. Hoboken, New Jersey: John Wiley \& Sons, Inc.; 2008.

[15] O'Hayre R, Cha S-W, Colella W, Prinz FB. Fuel Cell Fundamentals. Hoboken, New Jersey: John Wiley \& Sons, New York; 2006.

[16] Barsoukov E, Macdonald JR. Impedance Spectroscopy: Theory, Experiment, and Applications: Wiley-Interscience; 2005.

[17] Wojcik PT, Agarwal P, Orazem ME. A method for maintaining a constant potential variation during galvanostatic regulation of electrochemical impedance measurements. Electrochimica Acta. 1996;41(7-8):977-983.

[18] Gamry Instruments. Gamry Instruments Product Brochure: FC350 Fuel Cell Monitor. http://www.gamry.com/assets/Uploads/FC350-Brochure.pdf.

[19] Zhu WH, Payne RU, Nelms RM, Tatarchuk BJ. Equivalent Circuit Elements for PSpice Simulation of PEM Stacks at Pulse Load. Journal of Power Sources. 2008;178(1):197-206.

[20] Shinners SM. Modern Control System Theory and Design: John Wiley \& Sons; 1998.

[21] Gabrielli C. Identification of Electrochemical Processes by Frequency Response Analysis. Solatron Analytical AMETEK, Inc. 1998; Technical Report No. 004/83. 
[22] Hu JW, Zhang HM, Gang L. Diffusion-Convection/Electrochemical Model Studies on Polybenzimidazole (PBI) Fuel Cell Based On AC Impedance Technique. Energy Conversion and Management. 200;49(5):1019-1027.

[23] Macdonald DD, Urquidimacdonald M. Application of Kramers-Kronig Transforms in the Analysis of Electrochemical Systems 1. Polarization Resistance. Journal of the Electrochemical Society. 1985;132(10):2316-2319.

[24] Boukamp BA. A Linear Kronig-Kramers Transform Test for Immittance Data Validation. Journal of the Electrochemical Society. 1995;142(6):1885-1894.

[25] Macdonald JR. Impedance Spectroscopy - Old Problems and New Developments. Electrochimica Acta. 1990;35(10):1483-1492.

[26] Boukamp BA. A Nonlinear Least-Squares Fit Procedure for Analysis of Immittance Data of Electrochemical Systems. Solid State Ionics. 1986;20(1):31-44.

[27] Vladikova D. The Technique of the Differential Impedance Analysis Part I: Basics of the Impedance Spectroscopy. International Workshop "Advanced Techniques for Energy Sources Investigation and Testing"; 2004; Sofia, Bulgaria.

[28] Research Solutions \& Resources LLC. Electrochemistry Resources: Electrochemical Impedance: Diffusion and EIS: Warburg. http://www.consultrsr.com/resources/eis/diffusion.htm

[29] Bard AJ, Faulkner LR. Electrochemical Methods: Fundamentals and Applications: Wiley; 2001.

[30] Payne RU, Zhu Y, Zhu WH, Timper MS, Elangovan S, Tatarchuk BJ. Diffusion and Gas Conversion Analysis of Solid Oxide Fuel Cells at Loads via AC Impedance. International Journal of Electrochemistry. 2011. DOI:10.4061/2011/465452.

[31] Zhu WH, Payne RU, Tatarchuk BJ. PEM Stack Test and Analysis in a Power System at Operational Load via AC Impedance. Journal of Power Sources. 2007;168(1):211-217.

[32] Keithley JF. The Story of Electrical and Magnetic Measurements: From 500 BC to the 1940s: Wiley; 1999.

[33] Berg H. Johann Wilhelm Ritter - The Founder of Scientific Electrochemistry. Review of Polarography. 2008;54(2):99-103.

[34] Nelson RF. Power Requirements for Batteries in Hybrid Electric Vehicles. Journal of Power Sources. 2000;91(1):2-26.

[35] Karden E, Buller S, De Doncker RW. A Method for Measurement and Interpretation of Impedance Spectra for Industrial Batteries. Journal of Power Sources. 2000;85(1):72-78.

[36] Hejabi M, Oweisi A, Gharib N. Modeling of Kinetic Behavior of the Lead Dioxide Electrode in a Lead-Acid Battery by Means of Electrochemical Impedance Spectroscopy. Journal of Power Sources. 2006;158(2):944-948.

[37] Furukawa J, Takada T, Kanou T, Monma D, Lam LT, Haigh NP, et al. Development of UltraBattery. CSIRO Energy Technology, Australia Furukawa Battery CO. Ltd., Japan, 2006.

[38] Lam LT, Louey R. Development of Ultra-Battery for Hybrid-Electric Vehicle Applications. Journal of Power Sources. 2006;158(2):1140-1148. 
[39] Lam LT, Louey R, Haigh NP, Lim OV, Vella DG, Phyland CG, et al. VRLA Ultrabattery for High-Rate Partial-State-of-Charge Operation. Journal of Power Sources. 2007;174(1):16-29.

[40] Extreme Racing Owner's Manual. EnerSys Energy Products Inc., 2010.

[41] Zhu WH, Zhu Y, Tatarchuk BJ. A Simplified Equivalent Circuit Model for Simulation of $\mathrm{Pb}$-Acid Batteries at Load for Energy Storage Application. Energy Conversion and Management. 2011;52(8-9):2794-2799.

[42] Sakai T, Uehara I, Ishikawa H. R\&D on Metal Hydride Materials and Ni-MH Batteries In Japan. Journal of Alloys and Compounds. 1999;293:762-769.

[43] Shukla AK, Venugopalan S, Hariprakash B. Nickel-Based Rechargeable Batteries. Journal of Power Sources. 2001;100(1-2):125-148.

[44] Hariprakash B, Shukla AK, Venugoplan S. Editor-in-Chief: Jürgen G. Secondary Batteries - Nickel Systems I Nickel-Metal Hydride: Overview. Encyclopedia of Electrochemical Power Sources. Amsterdam: Elsevier; 2009. p. 494-501.

[45] Larminie J, Dicks A. Fuel Cell Systems Explained: J. Wiley; 2003.

[46] Mond L, Langer C, editors. A New Form of Gas Battery. Proceedings of the Royal Society of London; 1889; London: Harrison and Sons, St. Martin's Lane.

[47] Hoogers G. Fuel Cell Technology Handbook: Taylor \& Francis; 2002.

[48] Zhu WH, Payne RU, Cahela DR, Nelms RM, Tatarchuk BJ. Performance Analysis of PEM Stacks at Operational Loads Using Equivalent Circuit Models. Proceedings of the $42^{\text {nd }}$ Power Sources Conference; 2006; Philadelphia, PA.

[49] Costamagna P, Srinivasan S. Quantum Jumps in the PEMFC Science And Technology from the 1960s to the Year 2000 Part I. Fundamental Scientific Aspects. Journal of Power Sources. 2001;102(1-2):242-252.

[50] He RH, Li QF, Xiao G, Bjerrum NJ. Proton Conductivity of Phosphoric Acid Doped Polybenzimidazole and its Composites with Inorganic Proton Conductors. Journal of Membrane Science. 2003;226(1-2):169-184.

[51] Li QF, He RH, Jensen JO, Bjerrum NJ. Approaches and Recent Development of Polymer Electrolyte Membranes for Fuel Cells Operating above 100 Degrees C. Chemistry of Materials. 2003;15(26):4896-4915.

[52] Peighambardoust SJ, Rowshanzamir S, Amjadi M. Review of the Proton Exchange Membranes for Fuel Cell Applications. International Journal of Hydrogen Energy. 2010;35(17):9349-9384.

[53] Zhang JL, Tang YH, Song CJ, Xia ZT, Li H, Wang HJ, et al. PEM Fuel Cell Relative Humidity (RH) and its Effect on Performance at High Temperatures. Electrochimica Acta. 2008;53(16):5315-5321.

[54] Wainright JS, Wang JT, Weng D, Savinell RF, Litt M. Acid-Doped Polybenzimidazoles A New Polymer Electrolyte. Journal Of The Electrochemical Society. 1995;142(7):L121L123.

[55] Musto P, Karasz FE, Macknight WJ. Fourier-Transform Infrared-Spectroscopy on the Thermooxidative Degradation of Polybenzimidazole and of a Polybenzimidazole Polyetherimide Blend. Polymer. 1993;34(14):2934-2945. 
[56] Chung TS. A Critical Review of Polybenzimidazoles: Historical Development and Future R\&D. Journal of Macromolecular Science-Reviews In Macromolecular Chemistry and Physics. 1997;C37(2):277-301.

[57] Samms SR, Wasmus S, Savinell RF. Thermal Stability of Proton Conducting Acid Doped Polybenzimidazole in Simulated Fuel Cell Environments. Journal of the Electrochemical Society. 1996;143(4):1225-1232.

[58] Steininger H, Schuster M, Kreuer KD, Kaltbeitzel A, Bingol B, Meyer WH, et al. Intermediate Temperature Proton Conductors for PEM Fuel Cells Based on Phosphonic Acid as Protogenic Group: A Progress Report. Physical Chemistry Chemical Physics. 2007;9(15):1764-1773.

[59] Kreuer KD, Paddison SJ, Spohr E, Schuster M. Transport in Proton Conductors for Fuel-Cell Applications: Simulations, Elementary Reactions, and Phenomenology. Chemical Reviews. 2004;104(10):4637-4678.

[60] Schuster MFH, Meyer WH, Schuster M, Kreuer KD. Toward a New Type of Anhydrous Organic Proton Conductor Based on Immobilized Imidazole. Chemistry of Materials. 2004;16(2):329-337.

[61] Bouchet R, Siebert E. Proton Conduction in Acid Doped Polybenzimidazole. Solid State Ionics. 1999;118(3-4):287-299.

[62] Li QF, He RH, Berg RW, Hjuler HA, Bjerrum NJ. Water Uptake and Acid Doping of Polybenzimidazoles as Electrolyte Membranes for Fuel Cells. Solid State Ionics. 2004;168(1-2):177-185.

[63] Wannek C, Lehnert W, Mergel J. Membrane Electrode Assemblies for HighTemperature Polymer Electrolyte Fuel Cells Based on Poly(2,5-Benzimidazole) Membranes with Phosphoric Acid Impregnation via the Catalyst Layers. Journal of Power Sources. 2009;192(2):258-266.

[64] Bouchet R, Miller S, Duclot M, Souquet JL. A Thermodynamic Approach to Proton Conductivity in Acid-Doped Polybenzimidazole. Solid State Ionics. 2001;145(1-4):69-78.

[65] Fontanella JJ, Wintersgill MC, Wainright JS, Savinell RF, Litt M. High Pressure Electrical Conductivity Studies of Acid Doped Polybenzimidazole. Electrochimica Acta. 1998;43(10-11):1289-1294.

[66] Xu H, Song Y, Kunz HR, Fenton JM. Effect of Elevated Temperature and Reduced Relative Humidity on ORR Kinetics for PEM Fuel Cells. Journal of the Electrochemical Society. 2005;152(9):A1828-A1836.

[67] Ramani V, Kunz HR, Fenton JM. Stabilized Composite Membranes and Membrane Electrode Assemblies for Elevated Temperature/Low Relative Humidity PEFC Operation. Journal of Power Sources. 2005;152(1):182-188.

[68] Jalani NH, Ramani M, Ohlsson K, Buelte S, Pacifico G, Pollard R, et al. Performance Analysis and Impedance Spectral Signatures of High Temperature PBI-Phosphoric Acid Gel Membrane Fuel Cells. Journal of Power Sources. 2006;160(2):1096-103.

[69] Hu JW, Zhang HM, Hu J, Zhai YF, Yi BL. Two Dimensional Modeling Study of $\mathrm{PBI} / \mathrm{H}_{3} \mathrm{PO}_{4}$ High Temperature PEMFCs Based on Electrochemical Methods. Journal of Power Sources. 2006;160(2):1026-1034. 
[70] Hu JW, Zhang HM, Zhai YF, Liu G, Yi BL. 500h Continuous Aging Life Test on $\mathrm{PBI} / \mathrm{H}(3) \mathrm{PO}(4)$ High-Temperature PEMFC. International Journal of Hydrogen Energy. 2006;31(13):1855-1862.

[71] Hu JW, Zhang HM, Zhai YF, Liu G, Hu J, Yi BL. Performance Degradation Studies on $\mathrm{PBI} / \mathrm{H}_{3} \mathrm{PO}_{4}$ High Temperature PEMFC and One-Dimensional Numerical Analysis. Electrochimica Acta. 2006;52(2):394-401.

[72] Qi ZG, Buelte S. Effect of Open Circuit Voltage on Performance and Degradation of High Temperature PBI-H3PO4 Fuel Cells. Journal of Power Sources. 2006;161(2):11261132.

[73] Lobato J, Canizares P, Rodrigo MA, Linares JJ. PBI-Based Polymer Electrolyte Membranes Fuel Cells - Temperature Effects on Cell Performance and Catalyst Stability. Electrochimica Acta. 2007;52(12):3910-3920.

[74] Lobato J, Canizares P, Rodrigo MA, Linares JJ, Ubeda D, Pinar FJ. Study of the Catalytic Layer in Polybenzimidazole-Based High Temperature PEMFC: Effect of Platinum Content on the Carbon Support. Fuel Cells. 2010;10(2):312-319.

[75] Lobato J, Canizares P, Rodrigo MA, Linares JJ, Pinar FJ. Study of the Influence of the Amount of PBI-H(3)PO(4) in the Catalytic Layer of a High Temperature PEMFC. International Journal of Hydrogen Energy. 2010;35(3):1347-1355.

[76] Lobato J, Canizares P, Rodrigo MA, Pinar FJ, Ubeda D. Study of Flow Channel Geometry Using Current Distribution Measurement in a High Temperature Polymer Electrolyte Membrane Fuel Cell. Journal of Power Sources. 201;196(9):4209-4217.

[77] Boaventura M, Mendes A. Activation Procedures Characterization of MEA Based on Phosphoric Acid Doped PBI Membranes. International Journal of Hydrogen Energy. 2010;35(20):11649-11660.

[78] Andreasen SJ, Jespersen JL, Schaltz E, Kær SK. Characterisation and Modelling of a High Temperature PEM Fuel Cell Stack Using Electrochemical Impedance Spectroscopy. Fuel Cells. 2009;9(4):463-473.

[79] Zhang JL, Tang YH, Song CJ, Zhang JJ. Polybenzimidazole-Membrane-Based PEM Fuel Cell in the Temperature Range of 120-200 Degrees C. Journal of Power Sources. 2007;172(1):163-171.

[80] Chen CY, Lai WH. Effects of Temperature and Humidity on the Cell Performance and Resistance of a Phosphoric Acid Doped Polybenzimidazole Fuel Cell. Journal of Power Sources. 2010;195(21):7152-7159.

[81] Mamlouk M, Scott K. Analysis of High Temperature Polymer Electrolyte Membrane Fuel Cell Electrodes Using Electrochemical Impedance Spectroscopy. Electrochimica Acta. 2011;56(16):5493-5512.

[82] Jespersen JL, Schaltz E, Kaer SK. Electrochemical Characterization of a Polybenzimidazole-Based High Temperature Proton Exchange Membrane Unit Cell. Journal of Power Sources. 2009;191(2):289-296.

[83] Andreasen SJ, Vang JR, Kær SK. High Temperature PEM Fuel Cell Performance Characterisation with $\mathrm{CO}$ and $\mathrm{CO}(2)$ Using Electrochemical Impedance Spectroscopy. International Journal f Hydrogen Energy. 2011;36(16):9815-9830. 
[84] Oono Y, Sounai A, Hori M. Influence of the Phosphoric Acid-Doping Level in a Polybenzimidazole Membrane on the Cell Performance of High-Temperature Proton Exchange Membrane Fuel Cells. Journal of Power Sources. 2009;189(2):943-949.

[85] Modestov AD, Tarasevich MR, Filimonov VY, Zagudaeva NM. Degradation of High Temperature MEA with PBI-H(3)PO(4) Membrane in a Life Test. Electrochimica Acta. 2009;54(27):7121-7127.

[86] Lin HL, Hsieh YS, Chiu CW, Yu TL, Chen LC. Durability and Stability Test of Proton Exchange Membrane Fuel Cells Prepared From Polybenzimidazole/Poly(Tetrafluoro Ethylene) Composite Membrane. Journal of Power Sources. 2009;193(1):170-174. 